\title{
EVALUASI KEBIJAKAN PEMBANGUNAN DAERAH DI PROVINSI JAWA TENGAH 2019
}

\author{
Agus Fanar Syukri ${ }^{*}$, Wiwin Widiastuti ${ }^{2}$ \\ 1)Pusat Penelitian Kebijakan dan Manajemen Ilmu Pengetahuan, \\ Teknologi \& Inovasi - Lembaga Ilmu Pengetahuan Indonesia \\ 2)Badan Perencanaan Pembangunan, Penelitian \\ dan Pengembangan Daerah Provinsi Jawa Tengah \\ *)Korespondensi: agus.fanar.syukri@lipi.go.id
}

Article Histori:

Accepted: 16/2/2021

Review: 4/4/2021

Publish: 30/4/2021

\begin{abstract}
National and regional development to improve the economy and people's welfare is carried out with a sustainable concept based on natural resources and with an environmental perspective. To accelerate regional development in Central Java Province, Presidential Regulation number 79 of 2019 has been issued by setting 3 areas in Central Java as a focus, namely Bregasmalang, Kedungsepur and Purwomanggung and 5 other areas as supporting areas. To find out the results of regional development in all cities and districts in Central Java, a regional competitiveness index (RCI) was measured every year from 2018, in 2019 too when Presidential Regulation 79/2019 establised. From comparing the results of 2019 RCI in 3 focus areas and 5 supporting areas, it turns out that the RCI in the focus areas is not higher value than the supporting areas, Bregasmalang 5.86 of 12.0 was lower than Barlingmascakep 6.09; Purwomanggung 4.87 was lower than Subosukowonosraten 5.20, only Kedungsepur 6.35 was higher than other supporting area, indicating that the policy to determine 3 focus areas for accelerated development of the region of Central Java Province is not fully evidence-based. The recommendation is that the policy for regional development in Central Java Province in the future is based more on evidence, the results of RCI.
\end{abstract}

Keyword: Regional Competitiveness Index, Regional Development, Policy, Central Java Province

\section{PENDAHULUAN}

Pembangunan daerah untuk meningkatkan perekonomian dan kesejahteraan masyarakat harus dilakukan dengan kegiatan yang berkelanjutan. Keberhasilan proses pembangunan daerah dapat diukur dari tingkat daya saing daerah. Tingkat daya saing merupakan salah satu parameter dalam konsep pembangunan daerah berkelanjutan. Semakin tinggi tingkat daya saing daerah menunjukkan bahwa tingkat kesejahteraan masyarakat semakin tinggi. Model pengukuran daya saing daerah di Indonesia telah dikembangkan oleh Kementerian Riset dan Teknologi / Badan Riset dan Inovasi 
Nasional sejak tahun 2017. Pengukuran Indeks Daya Saing Daerah (IDSD) bertujuan untuk menggambarkan kondisi dan kemampuan suatu daerah dalam mengoptimalkan segala potensinya melalui peningkatan produktivitas, nilai tambah dan persaingan baik domestik maupun internasional, dengan pertumbuhan ekonomi yang tinggi dan berkelanjutan. RCI juga dapat diartikan sebagai cerminan tingkat produktivitas, kemajuan, persaingan dan kemandirian suatu daerah, dapat dijadikan sebagai dasar perencanaan pembangunan di tahun-tahun berikutnya (Ristek, 2019).

IDSD sangat penting sebagai alat untuk menilai keberhasilan pembangunan suatu daerah agar mampu bersaing dengan daerah lain, serta untuk mendukung daya saing nasional dalam persaingan global. Pengukuran IDSD diharapkan dapat menjadi salah satu dasar utama perumusan dan penetapan kebijakan nasional dan daerah yang mendorong sinergi program antar sektor untuk meningkatkan pertumbuhan ekonomi dan kesejahteraan masyarakat, di bawah kepemimpinan kepala daerah.

Presiden Republik Indonesia Joko Widodo telah mengeluarkan Peraturan Presiden nomor 79 tahun 2019 tentang percepatan pembangunan ekonomi di 3 wilayah di Jawa Tengah yaitu KendalDemak-Semarang-Salatiga Grobogan/ Purwodadi (Kedungsepur), PurworejoWonosobo- Magelang- Temanggung (Purwomanggung), dan Brebes- TegalPemalang (Bregasmalang); dan 5 bidang wilayah pengembangan lainnya sebagai bidang pendukung (Perpres 79, 2019)

Tujuan dari penelitian ini adalah mengevaluasi kebijakan percepatan pembangunan wilayah di Provinsi Jawa Tengah dalam Perpres 79/2019, dengan membandingkan hasil IDSD 3 wilayah fokus dengan 5 wilayah pendukung, apakah kebijakan pembangunan daerah itu diambil berdasarkan bukti. Perbandingan indeks daya saing diperlukan untuk melihat dan menjelaskan perbedaan tingkat keberhasilan pembangunan dan kemakmuran daerah, seperti yang dikemukakan oleh Kitson dkk (2004) "Perbandingan tersebut dapat bermanfaat karena menunjukkan fakta bahwa, dan panggilan untuk penjelasan mengapa, wilayah dan kota berbeda dalam kemakmuran ekonomi.

\section{KAJIAN LITERATUR}

Kebijakan publik yang diambil oleh pengambil kebijakan berbasis bukti akan memiliki tingkat kepercayaan yang lebih kuat seiring dengan berjalannya waktu, berbanding terbalik dengan kebijakan publik yang diambil berdasarkan opini atau subjektivitas pembuat kebijakan, seiring dengan berjalannya waktu tingkat kepercayaan akan penurunan (Sutcliffe \& Court, 2005), seperti yang ditunjukkan pada Gambar 1 berikut.

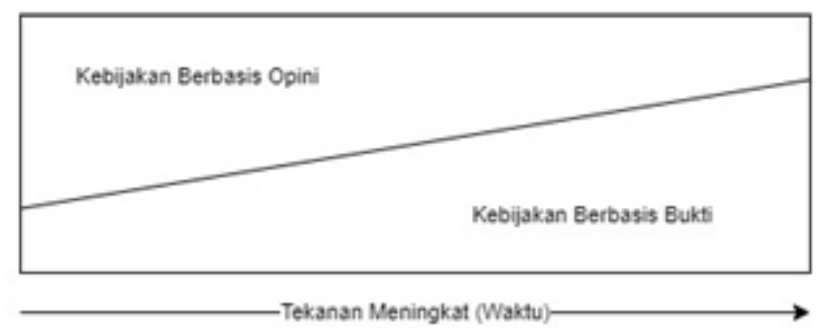

Gambar 1. Dinamika Kebijakan Berbasis Bukti

Daya Saing Daerah adalah kemampuan perekonomian daerah untuk mencapai tingkat kesejahteraan yang tinggi dan berkelanjutan dengan tetap terbuka terhadap persaingan domestik dan internasional (Bank Indonesia, 2008). Indeks daya saing dapat dijadikan potret atau tolak ukur keberhasilan pembangunan suatu daerah secara umum. Indeks ini juga dapat digunakan sebagai pengukur tingkat 
kesejahteraan penduduk dan merupakan potret pembangunan suatu daerah. Indeks Daya Saing Daerah dapat diartikan sebagai cerminan dari tingkat produktivitas, kemajuan, persaingan dan kemandirian suatu daerah.

Kementerian Riset dan Teknologi/ Badan Riset dan Inovasi Nasional (Kemenristek/ BRIN, 2019, 2020) mendefinisikan daya saing daerah sebagai nilai yang dihasilkan oleh interaksi yang kompleks antara faktor input, output, dan outcome di daerahnya masing-masing, dengan faktor input sebagai faktor utama. Faktor pembentuk daya saing daerah yaitu kemampuan daerah, yang selanjutnya akan menentukan kinerja keluaran yang merupakan inti dari kinerja perekonomian. Esensi kinerja ekonomi adalah upaya meningkatkan daya saing suatu perekonomian yang dapat meningkatkan kesejahteraan masyarakat yang tinggal di daerahnya. Ukuran kesejahteraan mempunyai arti yang sangat luas, indikatornya bisa berupa produktivitas tenaga kerja, PDRB per kapita atau tingkat kesempatan kerja. IDSD dapat dijadikan potret atau tolak ukur keberhasilan pembangunan suatu daerah. Indeks ini juga dapat digunakan sebagai pengukur tingkat kesejahteraan penduduk dan merupakan potret perkembangan suatu daerah.

Kategori dan nilai IDSD di tahun 2019 adalah 0,00 sampai 12,0 terbagi menjadi 4 level yaitu rendah dengan nilai 0,00 sampai dengan 3,00; sedang 3,01-6,00, tinggi 6,019,00 dan sangat tinggi 9,01-12.00, seperti yang ditunjukkan pada tabel 1. Sedangkan komponen IDSD terdiri dari 4 aspek yaitu 12 pilar dan 23 dimensi sebagaimana ditunjukkan pada Tabel 2, serta 78 indikator yang tidak ditampilkan di table 1 .

Table 1. Kategori dan Nilai IDSD 2019

\begin{tabular}{ccc} 
NO & KATEGORI & NILAI \\
\hline $\mathbf{1}$ & Rendah & $0,00-3,00$ \\
\hline $\mathbf{2}$ & Sedang & $3,01-6,00$ \\
\hline $\mathbf{3}$ & Tinggi & $6,01-9,00$ \\
\hline $\mathbf{4}$ & Sangat Tinggi & $9,01-12,00$
\end{tabular}

Menurut Tarigan (2005), keunggulan komparatif adalah kegiatan ekonomi yang jika dibandingkan lebih menguntungkan bagi pembangunan daerah. Lebih lanjut menurut Tarigan (2005) istilah comparative advantage (keunggulan komparatif) pertama kali dikemukakan oleh David Ricardo (1917). Dalam teori ini, Ricardo membuktikan bahwa jika ada dua negara yang saling berdagang satu sama lain dan masing-masing negara berkonsentrasi pada ekspor barang yang negara tersebut memiliki keunggulan komparatif, kedua negara tersebut akan beruntung. Ternyata ide ini tidak hanya berguna dalam perdagangan internasional tetapi juga sangat penting dalam perekonomian daerah. Sedangkan keunggulan bersaing merupakan keunggulan yang dapat diciptakan dan dikembangkan. Ini adalah ukuran daya saing suatu kegiatan, kemampuan suatu negara atau daerah untuk memasarkan produknya ke luar daerah atau ke luar negeri (Porter, 2004).

Tabel 2. Komponen IDSD

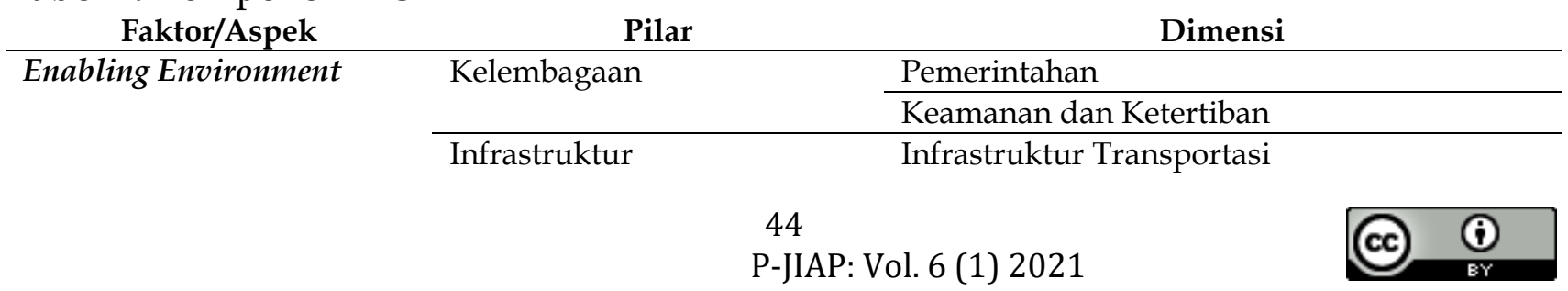




\begin{tabular}{|c|c|c|}
\hline Faktor/Aspek & Pilar & Dimensi \\
\hline & & Infrastruktur Air Bersih dan Kelistrikan \\
\hline & Ekonomi Regional & Keuangan Daerah \\
\hline & & Stabilitas Ekonomi \\
\hline \multirow[t]{3}{*}{ Sumber Daya Manusia } & Kesehatan & Kesehatan \\
\hline & Pedidikan an Ketrampilan & Pendidikan \\
\hline & & Ketrampilan \\
\hline \multirow[t]{7}{*}{ Pasar } & Efisiensi Pasar Produk & Pwesaingan Domestik \\
\hline & & Pajak dan Retribusi \\
\hline & & Stabilitas Pasar \\
\hline & Ketenagakerjaan & Tenaga Kerja \\
\hline & & Kapasitas Tenaga Kerja \\
\hline & Akses Keuangan & Akses Keuangan \\
\hline & Ukuran Pasar & Ukuran Pasar \\
\hline \multirow[t]{7}{*}{ Ekosistem Inovasi } & Dnamika Bisnis & Peraturan \\
\hline & & Kewirausahaan \\
\hline & Kapasitas Inovasi & Interaksi dan Keragaman \\
\hline & & Riset dan Pengembangan \\
\hline & Kesiapan Teknologi & Komersialisasi \\
\hline & & Telematika \\
\hline & & Teknologi \\
\hline
\end{tabular}

Menurut Tarigan (2005) seorang perencana daerah harus memiliki kemampuan menganalisis potensi ekonomi daerahnya. Dalam hal ini, kemampuan pemerintah daerah untuk melihat sektorsektor yang memiliki kelebihan/ kekurangan di daerahnya menjadi semakin penting. Berdasarkan hasil riset Pujiati (2009) dengan analisis Tipologi Klassen disimpulkan bahwa terdapat tujuh kabupaten/kota yang termasuk klasifikasi cepat maju dan cepat tumbuh yaitu Kudus, Sukoharjo, Cilacap, Semarang, Karangayar, Kota Surakarta dan Kota Pekalongan; empat kabupaten/kota yang termasuk klasifikasi daerah maju tetapi tertekan, yaitu Kendal, Kota Magelang, Kota Semarang dan Kota Salatiga; sembilan kabupaten/kota yang termasuk klasifikasi berkembang cepat yaitu Banyumas, Purbalingga, Boyolali, Klaten, Grobogan, Tegal, Brebes, Pati dan Kota Tegal ; dan lima belas kabupaten/kota lainnya termasuk klasifikasi relatif tertinggal. Menurut Destriningsih (2019) berdasarkan analisis Tipologi Kelas,
Provinsi Jawa Tengah berada pada kuadran empat yang termasuk dalam wilayah yang dikategorikan sebagai daerah yang relatif tertinggal, hal ini dapat terjadi karena daerah rujukan dalam penelitian adalah seluruh provinsi yang ada di Pulau Jawa. Ada tingkat PDRB yang tidak seimbang antara enam provinsi yang ada. Hasil penelitian Destriningsih (2019) pula atas Connectivity quotient (CQ) Provinsi Jawa Tengah dibandingkan dengan provinsi di Pulau Jawa dinilai memiliki posisi yang kurang menguntungkan dalam berinteraksi dengan provinsi lain. Sedangkan CQ masing-masing kabupaten / kota di Provinsi Jawa Tengah dibandingkan dengan Provinsi Jawa Tengah terlihat bahwa terdapat 19 kabupaten / kota dari 35 kabupaten / kota di Jawa Tengah yang tergolong daerah yang memiliki tingkat aksesibilitas tinggi, yaitu Banjarnegara, Purworejo, Kabupaten Wonosobo, Magelang, Boyolali, Klaten, Sukoharjo, Grobogan, Kudus, Demak, Semarang, Temanggung, Kendal, Batang, Kota 
Magelang, Kota Surakarta, Kota Salatiga, Kota Semarang, dan Kota Pekalongan.

Syukri dan Widiastuti mengemukakan bahwa dari perbandingan hasil IDSD yang diukur pada tahun 2020 dengan rentang nilai yang berubah dari tahun 2019 yang 0,00-12,00 menjadi 0,00 sampai dengan 5,$00 ; 3$ area fokus pengembangan wilayah dan 5 area pendukung, ternyata IDSD di area fokus tidak lebih tinggi nilainya dibandingkan wilayah pendukung, Bregasmalang 3,20 lebih rendah dari Barlingmascakep 3,21 dan Petanglong 3,55; Kedungsepur 3,50 lebih rendah dari Petanglong 3,55; Purwomanggung 3,36 lebih rendah dari Subosukowonosraten $\quad 3,50 \quad$ yang menunjukkan bahwa hasil implementasi kebijakan penetapan 3 wilayah untuk percepatan pembangunan wilayah Provinsi Jawa Tengah yang diperkuat oleh Perpres 79/2019 belum diubah sesuai rekomendasi agar kebijakan yang diambil oleh policy maker berbasis bukti yaitu hasil IDSD tahun 2020.

Sementara itu, (Winarno, 2016:135) berpendapat bahwa tugas penerapan/ implementasi ialah membuat suatu hubungan/jaringan untuk mempermudah tujuan-tujuan kebijakan bisa diwujudkan atau dilaksanakan sebagai akibat dari suatu kegiatan pemerintah. Dengan demikian tugas penerapan/implementasi adalah meliputi terbentuknya sistem penyampaian kebijakan (a policy delivery system), yaitu merancang dan menjalankan peralatan- peralatan tertentu untuk mencapai tujuantujuan sesuai dengan harapan.

Implementasi kebijakan umum secara sederhana adalah sebagai suatu proses merealisasikan peraturan-peraturan ke dalam bentuk tindakan (action). Secara praktek/praktis pelaksanaan kebijakan publik merupakan suatu proses yang sangat kompleks dan terkadang bermuatan politis karena bentuknya intervensi berbagai kepentingan (Agustino, 2017:126).

\section{METODE PENELITIAN}

Penelitian ini merupakan penelitian kuantitatif dengan menggunakan metode analisis komparatif. Penelitian difokuskan pada perbandingan nilai IDSD Provinsi Jawa Tengah tahun 2019 dengan menggunakan model pengukuran IDSD yang dikembangkan Kemenristek/ BRIN dan strategi peningkatan daya saing daerah. Penelitian menggunakan data sekunder dari Kemenristek/ BRIN dan BAPPEDA Provinsi Jawa Tengah. Data tersebut terdiri dari nilai indeks daya saing daerah kota dan kabupaten di Provinsi Jawa Tengah, data kondisi dan karakteristik daerah, arah pembangunan daerah di Provinsi Jawa Tengah, serta peran \& fungsi pembangunan daerah. Kerangka Berpikir yang digunakan dalam penelitian ini seperti ditunjukkan untuk menjawab apakah Perpres 79/2019 merupakan kebijakan yang berbasis bukti jika dilihat dari perspektif hasil IDSD 2019 sebagaimana gambar 2 berikut.

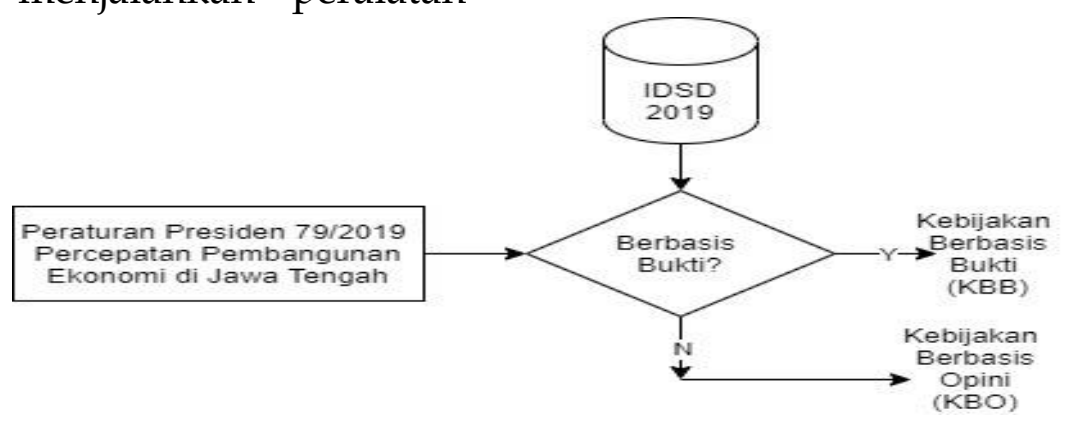

Gambar 2. Kerangka Berpikir Penelitian 
Analisis yang digunakan dalam penelitian ini adalah analisis deskriptif komparatif. Menurut Fafurida (2012), informasi penting tentang pembangunan daerah diperlukan agar perencanaan lebih mudah disusun. Analisis deskriptif merupakan salah satu teknik analisis untuk merumuskan arah rencana dan strategi pembangunan daerah. Hasil analisis tersebut dapat digunakan sebagai dasar penyusunan pembangunan daerah. Analisis deskriptif ini pada dasarnya merupakan deskripsi dari suatu proses yang mencakup pencarian dan pengungkapan informasi relevan yang terkandung dalam data. Tujuan dari analisis deskriptif menurut Pravitasari (2009) adalah untuk memberikan gambaran dan interpretasi dari hasil analisis yang disajikan dalam bentuk grafik dan gambar, serta untuk menghitung pengukuran deskriptif. Sedangkan komparatif adalah membandingkan antar wilayah fokus dan wilayah pendukung, apakah nilai-nilai indeks yang dimiliki oleh masing-masing wilayah yang ditentukan sebagai wilayah fokus atau wilayah pendukung nilainya berbeda, nilai fokus apakah lebih tinggi nilai indeksnya dibandingkan wilayah pendukung yang ada di sekitar wilayah fokus.

\section{HASIL DAN PEMBAHASAN}

\section{Hasil}

Dalam rangka meningkatkan investasi dan pertumbuhan ekonomi di daerah yang berdampak pada perekonomian daerah dan nasional, maka dilakukan percepatan pembangunan yang dijabarkan dalam Perpres 79/2019 dengan membentuk 8 (delapan) wilayah pembangunan seperti ditunjukkan di Gambar 3 berikut.

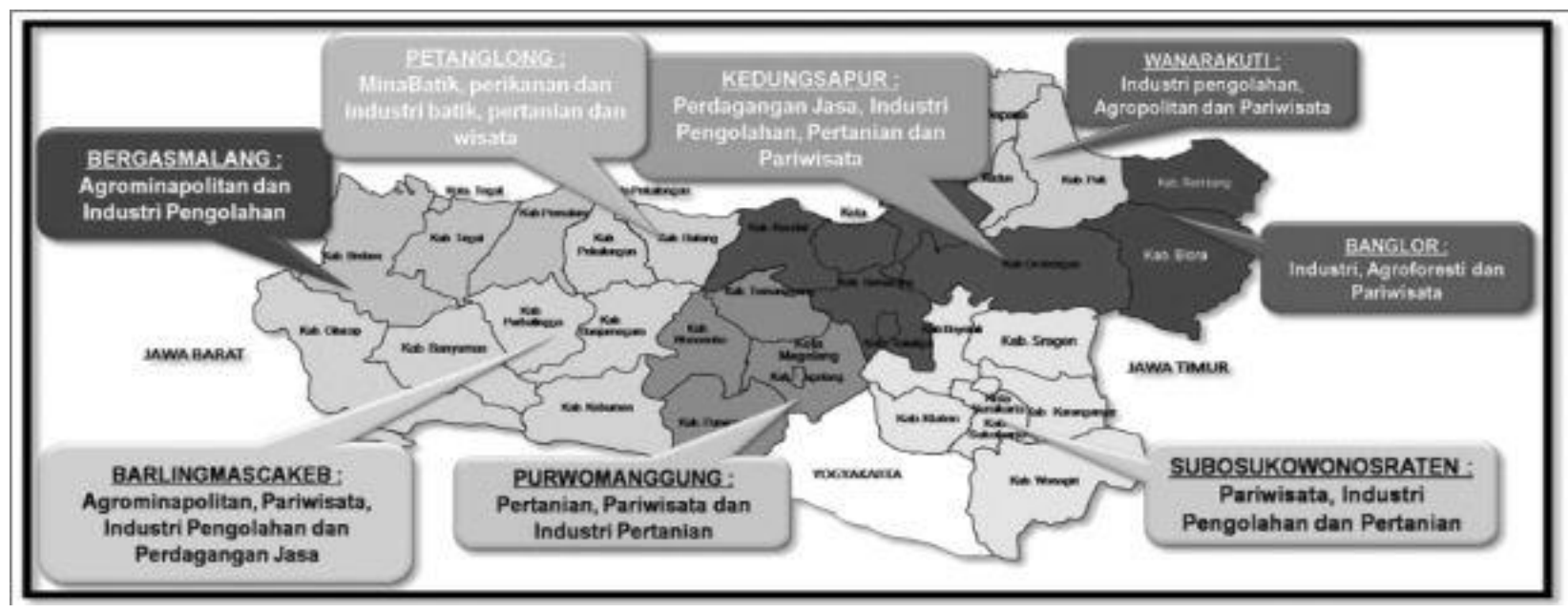

Gambar 3. 8 Wilayah Pembangunan Provinsi Jawa Tengah 2019

Dari 8 wilayah pembangunan di Provinsi Jawa Tengah yang ditunjukkan pada Gambar 3 tersebut ditetapkan 3 (tiga) kawasan fokus utama, yaitu (1) Kawasan Kedungsepur: Kendal-Demak - Semarang Salatiga -Grobogan/Purwodadi; (2) Kawasan Purwomanggung: PurworejoWonosobo-Magelang - Temanggung; Kawasan Bregasmalang : Brebes - Tegal -
Pemalang. Untuk mendukung dan memberikan nilai tambah bagi pembangunan 3 wilayah fokus utama tersebut, maka dibentuk pula 5 (lima) area wilayah pembangunan penunjang, yang meliputi (1) Kawasan Barlingmascakeb: Banjarnegara- Purbalingga- BanyumasCilacap-Kebumen; (2) Kawasan Petanglong: Pekalongan - Batang; (3) Kawasan 
Wanarakuti: Jepara - Kudus - Pati; (4)

Kawasan Banglor: Rembang - Blora; (5)

Kawasan Subosukawonosraten: SurakartaBoyolali- Sukoharjo- Karanganyar-
Wonogiri - Sragen - Klaten. Sedangkan potensi ekonomi ditunjukkan di Tabel 3. tentang Wilayah Pengembangan Provinsi Jawa Tengah dan Potensi Ekonomi berikut.

Tabel 3. Wilayah Pengembangan Provinsi Jawa Tengah dan Potensi Ekonomi

\begin{tabular}{|c|c|c|c|}
\hline Kode & Wilayah & Kabupaten/Kota & Potensi Ekonomi \\
\hline $\mathrm{A}$ & Bregasmalang & $\begin{array}{l}\text { Brebes, Kota Tegal, Kabupaten } \\
\text { Tegal, Pemalang }\end{array}$ & $\begin{array}{l}\text { Agrominapolitan dan industri } \\
\text { pengolahan }\end{array}$ \\
\hline B & Petanglong & $\begin{array}{l}\text { Pekalongan, Batang, Kota } \\
\text { Pekalongan }\end{array}$ & $\begin{array}{l}\text { Mina Batik, perikanan , industri } \\
\text { batik, pertanian, pariwisata }\end{array}$ \\
\hline $\mathrm{C}$ & Kedungsepur & $\begin{array}{l}\text { Kendal, Demak, Ungaran } \\
\text { (Kabupaten Semarang), Kota } \\
\text { Semarang, Kota Salatiga, } \\
\text { Purwodadi (Kabupaten } \\
\text { Grobogan) }\end{array}$ & $\begin{array}{l}\text { Jasa perdagangan, industri } \\
\text { pengolahan, agriculture, pariwisata }\end{array}$ \\
\hline $\mathrm{D}$ & Wanarakuti & Jepara, Kudus, Pati & $\begin{array}{l}\text { Industri engolahan, agropolitan, } \\
\text { pariwisata }\end{array}$ \\
\hline E & Banglor & Rembang, Blora & Industri, agroforestry, pariwisata \\
\hline $\mathrm{F}$ & $\begin{array}{l}\text { Subosukowono- } \\
\text { sraten }\end{array}$ & $\begin{array}{l}\text { Surakarta, Boyolali, Sukoharjo, } \\
\text { Karanganyar, Wonogiri, } \\
\text { Sragen, and Klaten }\end{array}$ & $\begin{array}{l}\text { Pariwisata, industri pengolahan, } \\
\text { pertanian }\end{array}$ \\
\hline G & Purwo-manggung & $\begin{array}{l}\text { Purworejo, Wonosobo, } \\
\text { kabupaten Magelang, Kota } \\
\text { Magelang, Temanggung }\end{array}$ & $\begin{array}{l}\text { Pertanian, pariwisata, industri } \\
\text { pertanian }\end{array}$ \\
\hline $\mathrm{H}$ & Barlingmascakep & $\begin{array}{l}\text { Banjarnegara, Purbalingga, } \\
\text { Banyumas, Cilacap, Kebumen }\end{array}$ & $\begin{array}{l}\text { Agrominapolitan, pariwisata, } \\
\text { industri pengolahan, jasa } \\
\text { perdagangan }\end{array}$ \\
\hline
\end{tabular}

Kedelapan Wilayah Pembangunan Provinsi Jawa Tengah tersebut di Gambar 3 dan Tabel 3 terbagi menjadi sumbu pengembangan utara dan selatan, dengan sumbu pengembangan utara Bregasmalang (A)- Petanglong (B)- Kedungsepur (C)Wanarakuti (D)- Banglor (E) dan sumbu pengembangan selatan Subosukawonosraten (F)- Purwomanggung (G) Barlingmascakeb (H). Masing-masing wilayah pengembangan memiliki potensi ekonomi yang telah diidentifikasi dalam dokumen RTRW Provinsi Jawa Tengah tahun 2009-2029 (Bappeda, 2019).
Pilar utama Percepatan dan Pemerataan Pembangunan Ekonomi Daerah di Jawa Tengah adalah: (1) pengembangan sektor dan komoditas unggulan; (3) memperkuat konektivitas dan sistem logistik antar pusat pertumbuhan; (4) pengembangan pusat-pusat pertumbuhan ekonomi baru dalam rangka pemerataan; dan (5) peningkatan kapasitas sumber daya manusia, ilmu pengetahuan dan teknologi (Iptek). Selanjutnya hasil pengukuran IDSD di seluruh kota dan kabupaten di Provinsi Jawa Tengah yang berjumlah 35 (tiga puluh lima) tahun 2019 ditunjukkan pada Tabel 4.

Tabel 4. Nilai IDSD Kabupaten dan Kota Provinsi Jawa Tengah Tahun 2019

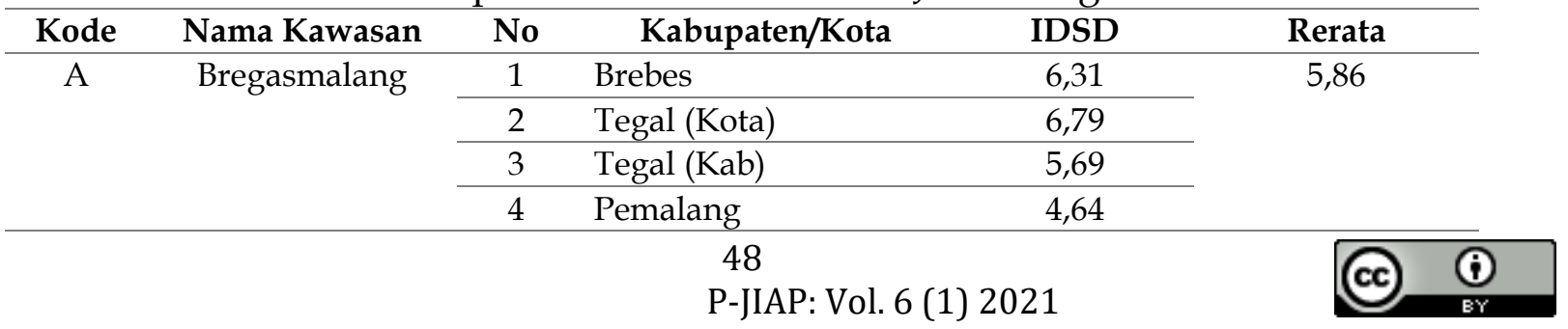




\begin{tabular}{|c|c|c|c|c|c|}
\hline Kode & Nama Kawasan & No & Kabupaten/Kota & IDSD & Rerata \\
\hline \multirow[t]{3}{*}{ B } & \multirow[t]{3}{*}{ Petanglong } & 5 & Pekalongan (Kab) & 5,82 & \multirow[t]{3}{*}{6,09} \\
\hline & & 6 & Batang & 6,09 & \\
\hline & & 7 & Pekalongan (Kota) & 6,34 & \\
\hline \multirow[t]{6}{*}{$\mathrm{C}$} & \multirow[t]{6}{*}{ Kedungsepur } & 8 & Kendal & 7,80 & \multirow[t]{6}{*}{6,35} \\
\hline & & 9 & Demak & 4,71 & \\
\hline & & 10 & $\begin{array}{l}\text { Ungaran } \\
\text { (Semarang/Kab) }\end{array}$ & 6,40 & \\
\hline & & 11 & Semarang (Kota) & 7,37 & \\
\hline & & 12 & Salatiga (Kota) & 6,45 & \\
\hline & & 13 & $\begin{array}{l}\text { Purwodadi } \\
\text { (Grobogan) }\end{array}$ & 5,38 & \\
\hline \multirow[t]{3}{*}{$\mathrm{D}$} & \multirow[t]{3}{*}{ Wanarakuti } & 14 & Jepara & 3,57 & \multirow[t]{3}{*}{5,30} \\
\hline & & 15 & Kudus & 5,55 & \\
\hline & & 16 & Pati & 6,76 & \\
\hline \multirow[t]{2}{*}{$\mathrm{E}$} & \multirow[t]{2}{*}{ Banglor } & 17 & Rembang & 7,05 & \multirow[t]{2}{*}{5,69} \\
\hline & & 18 & Blora & 4,33 & \\
\hline \multirow[t]{7}{*}{$\mathrm{F}$} & \multirow{7}{*}{$\begin{array}{l}\text { Subosuko- } \\
\text { wonosraten }\end{array}$} & 19 & Surakarta (Kota) & 7,71 & \multirow[t]{7}{*}{5,20} \\
\hline & & 20 & Boyolali & 5,88 & \\
\hline & & 21 & Sukoharjo & 2,21 & \\
\hline & & 22 & Karanganyar & 3,13 & \\
\hline & & 23 & Wonogiri & 7,60 & \\
\hline & & 24 & Sragen & 4,70 & \\
\hline & & 25 & Klaten & 5,15 & \\
\hline \multirow[t]{5}{*}{ G } & \multirow[t]{5}{*}{ Purwomanggung } & 26 & Purworejo & 5,02 & \multirow[t]{5}{*}{4,87} \\
\hline & & 27 & Wonosobo & 4,32 & \\
\hline & & 28 & Magelang (Kab) & 4,83 & \\
\hline & & 29 & Magelang (Kota) & 6,15 & \\
\hline & & 30 & Temanggung & 4,04 & \\
\hline \multirow[t]{5}{*}{$\mathrm{H}$} & \multirow[t]{5}{*}{ Barlingmascakep } & 31 & Banjarnegara & 4,03 & \multirow[t]{5}{*}{4,66} \\
\hline & & 32 & Purbalingga & 3,30 & \\
\hline & & 33 & Banyumas & 5,97 & \\
\hline & & 34 & Cilacap & 5,43 & \\
\hline & & 35 & Kebumen & 4,56 & \\
\hline
\end{tabular}

\section{Pembahasan}

Dari hasil penelitian Pujiati (2009) yang melihat pembangunan kabupaten dan kota di Jawa Tengah berdasarkan Tipologi Klassen dan Distriningsih (2019) melihat berbasis Tipologi Kelas, mereka menyimpulkan bahwa pembangunan kapubaten/kota dapat diklasifikasikan menjadi 4 (empat) kawasan, yaitu cepat maju dan cepat tumbuh, maju tetapi tertekan, berkembang cepat dan relatif tertinggal. Kabupaten dan kota diklasifikasikan secara mandiri, belum dilihat dan dibandingkan dengan daerah sekitarnya, padahal perkembangan ekonomi pasti mendapatkan pengaruh timbal balik dari daerah sekitarnya (Tarigan, 2005), baik produk, jasa maupun tenaga kerja.

Untuk mempercepat pembangunan wilayah, bukan berbasis kepada kabupaten/kota saja, tetapi beberapa kabupaten dan kota yang berdekatan disatukan dalam wilayah pengembangan, maka Bappeda Provinsi Jawa Jawa Tengah Sesuai dalam dokumen Arah Pengembangan Wilayah Provinsi Jawa Tengah (Bappeda, 2017) membentuk 
wilayah-wilayah pengembangan yang berjumlah 8 (delapan) berbasis kepada kedekatan daerah dan keunggulan potensi ekonominya yaitu pertanian, industri, dan pariwisata, dengan memperhatikan kelestarian alam dan pemerataan pembangunan wilayah yang berkelanjutan. Konsep pengembangan wilayah di Provinsi Jawa Tengah tersebut diperkuat dengan Perpres 79/2019.

Apakah konsep pengembangan 8 wilayah di Provinsi Jawa Tengah telah tepat sebagia kebijakan yang disusun berbasis pada bukti? Dari perbandingan hasil IDSD tahun 2019 di 3 (tiga) wilayah fokus dan 5 (lima) wilayah pendukung di Provinsi Jawa Tengah ditunjukkan pada Tabel 4, ternyata nilai IDSD Bregasmalang (A) 5,86 lebih rendah dari Petanglong (B) 6,09; dan nilai IDSD Purwomanggung (G) 4,87 lebih rendah dari Subosukowonosraten $(\mathrm{F})$ 5,20; hanya nilai IDSD Kedungsepur (C) 6,35 saja yang lebih tinggi dari wilayah-wilayah sekitarnya. Hal ini menunjukkan bahwa kebijakan penetapan 3 (tiga) kawasan fokus percepatan pembangunan kawasan di Perpres 79/2019 belum sepenuhnya berdasarkan bukti, salah satunya adalah dari hasil pengukuran IDSD Provinsi Jawa tahun 2019.

\section{PENUTUP}

Untuk percepatan pembangunan daerah di Provinsi Jawa Tengah, telah dikeluarkan Perpres nomor 79 tahun 2019 dengan menetapkan 3 wilayah di Jawa Tengah sebagai fokus, yaitu wilayah Bregasmalang, Kedungsepur, dan Purwomanggung serta 5 wilayah lainnya Petanglong, Wanarakuti, Banglor, Sobosukowonosraten dan Barlingmascakep sebagai wilayah pendukung.

Hasil pembangunan daerah di seluruh kota dan kabupaten di Provinsi Jawa
Tengah sudah diukur menggunakan Indeks Daya Saing Daerah (IDSD) tahun 2019, dan dari perbandingan hasil IDSD 2019 di 3 (tiga) fokus area dan 5 (lima) wilayah pendukung ternyata IDSD di area fokus tidak lebih tinggi nilainya; Bregasmalang 5,86 lebih rendah dari Petanglong 6.09; dan Purwomanggung 4,87 lebih rendah dari Subosukowonosraten 5,20; hanya nilai IDSD Kedungsepur 6,35 saja yang lebih tinggi dari wilayah-wilayah lainnya; menunjukkan bahwa kebijakan penetapan 3 kawasan percepatan pembangunan kawasan belum sepenuhnya berdasarkan bukti, yaitu hasil IDSD tahun 2019.

Rekomendasi agar kebijakan pembangunan daerah di Provinsi Jawa Tengah ke depan lebih berbasis bukti, yaitu hasil IDSD. Sedangkan percepatan pembangunan daerah lebih difokuskan pada kelebihan sumber daya yang dimiliki kota dan kabupaten dengan daerah terkait, dengan melihat keunggulan daerah sekitarnya yang menjadi tempat percepatan pembangunan.

Strategi untuk meningkatkan IDSD Provinsi Jawa Tengah ke depan yang telah diambil oleh Gubernur Jawa Tengah bersama DPRD Provinsi Jawa Tengah adalah dengan tetap mensinergikan pembangunan daerah di Jawa Tengah dengan membangun wilayah-wilayah yang merupakan gabungan dari beberapa kota dan kabupaten dengan mengoptimalkan sumber daya yang tersedia di kota dan kabupaten dalam pengembangan wilayah dan fokus pada meningkatkan nilai indeks yang masih rendah di wilayah pengembangan, dengan saling mengisi antara kabupaten dengan kota atas indikator-indikator yang telah tinggi 
nilainya untuk direplikasi program dan kegiatannya di kabupaten/kota lain yang perlu ditingkatkan nilai indeksnya.

\section{DAFTAR PUSTAKA}

Badan Perencanaan Pembangunan, Penelitian dan Pengembangan Daerah Provinsi Jawa Tengah. (2017). Rancanagan Akhir RPJMD Jawa Tengah Tahun 2018-2023.

Badan Perencanaan Pembangunan, Penelitian dan Pengembangan Daerah Provinsi Jawa Tengah. (2019). Analisa Data dan Informasi Kawasan Pengembangan Wilayah Jawa Tengah. Bank Indonesia, Pusat Pendidikan dan Studi Kebanksentralan (PPSK), Laboratorium Penelitian, Pengabdian pada Masyarakat dan Pengkajian Ekonomi (LP3E) Fakultas Ekonomi Universitas Padjadjaran. (2008). Profil dan Pemetaan Daya Saing Ekonomi Daerah Kabupaten Kota di Indonesia. Jakarta: PT Rajagrafindo Persada.

Destiningsih, R, Achsa, A, Septiani, Y. (2019). Analisis Potensi Wilayah Provinsi Jawa Tengah - Studi Kasus Tahun 2010-2016. Jurnal REP (Riset Ekonomi Pembangunan) Volume 4 Nomor 1.

Fafurida. (2012). Analysis of Inter Sectoral Linkages in Semarang Regency. Economic Journal of Emerging Markets, 4(1):15-24.

Kementerian Riset dan Teknologi / Badan

Riset dan Inovasi Nasional. (2019).

Laporan Hasil Pemetaan Indeks Daya Saing Daerah (IDSD) se-Indonesia. https://indeks.inovasi.ristekbrin.go.i

$\mathrm{d} /$ ?menu=informasi\&id=5\&id_detail $=$ 11 (diakses 31 September 2020)

Kementerian Riset dan Teknologi / Badan Riset dan Inovasi Nasional. (2020).
Panduan Indeks Daya Saing Daerah Tahun 2020.

Kitson, M., Martin, R. and Tyler, P. (2004). Regional Competitiveness: An Elusive yet Key Concept? Regional Studies, 38 (9): 991 - 999.

Peraturan Presiden Nomor 79 Tahun 2019.

Percepatan Pembangunan Ekonomi

Kawasan Kendal-Demak-SemarangSalatiga-Grobogan,

Kawasan

Purworejo-Wonosobo-Magelang-

Temanggung, dan Kawasan BrebesTegal-Pemalang.

https://jdih.setkab.go.id/PUUdoc/17

5980/Perpres_Nomor_79_Tahun_2019 .pdf (diakses 31 September 2020)

Porter, Michael E. (2004). Building the microeconomic foundations of prosperity: Findings from the business competitiveness index. The Global Competitiveness Report 2003-2004, Oxford University Press: New York.

Pravitasari, A.E. (2009). Dinamika Perubahan Disparitas Regional di Pulau Jawa sebelum dan Setelah Kebijakan Otonomi Daerah. Tesis Sekolah Pascasarjana Institut Pertanian Bogor. Bogor. 179 hlm.

Pujiati, Amin. (2009). Analisis Kawasan Andalan di Jawa Tengah. Jurnal Aset Vol 11, No.2. September 2009. 117-128. ISSN 1693-928X.

Sutcliffe, Sophie; Court, Julius. (2005). Evidence-Based Policymaking: What is it? How does it work? What relevance for developing countries? Overseas Development Institute.

Syukri, A.F; Widiastuti, W. (2020). Evaluation of Central Java Province Acceleration Regional Development Strategy Policy. The Ist International Congress on Regional Economic Development, Information Technology, and Sustainable Business (Ist INCREDIBLE). 
Tarigan, S. (2005). Perencanaan Pembangunan Wilayah. Bumi Aksara. 